\title{
Spectrum of rheumatic heart disease in single patient
}

\author{
Iranna S Hirapur, Ravindran Rajendran, Vikram B Kolhari, Shivakumar Bhairappa
}

Department of Cardiology, Sri Jayadeva Institute of

Cardiovascular Sciences and Research, Bangalore, Karnataka, India

\section{Correspondence to} Dr Shivakumar Bhairappa, snbhairappa@gmail.com

\section{DESCRIPTION}

Rheumatic heart disease (RHD) is still highly prevalent in developing countries and accounts for sizeable cardiovascular morbidity. The mitral valve is the most commonly involved valve. Since its introduction by Inoue et $a l^{1}$ in 1984 as an alternative to surgical mitral commissurotomy for treatment of rheumatic mitral stenosis (MS), percutaneous transvenous mitral commissurotomy (PTMC) has been successfully and safely performed in large series of patients at numerous centres. Excellent long-term results obtained after PTMC, like those of an open mitral valvotomy, are far superior to those after a closed mitral valvotomy (CMV). ${ }^{2}$

We presented a case of a patient with mitral restenosis after CMV and PTMC with a left atrium
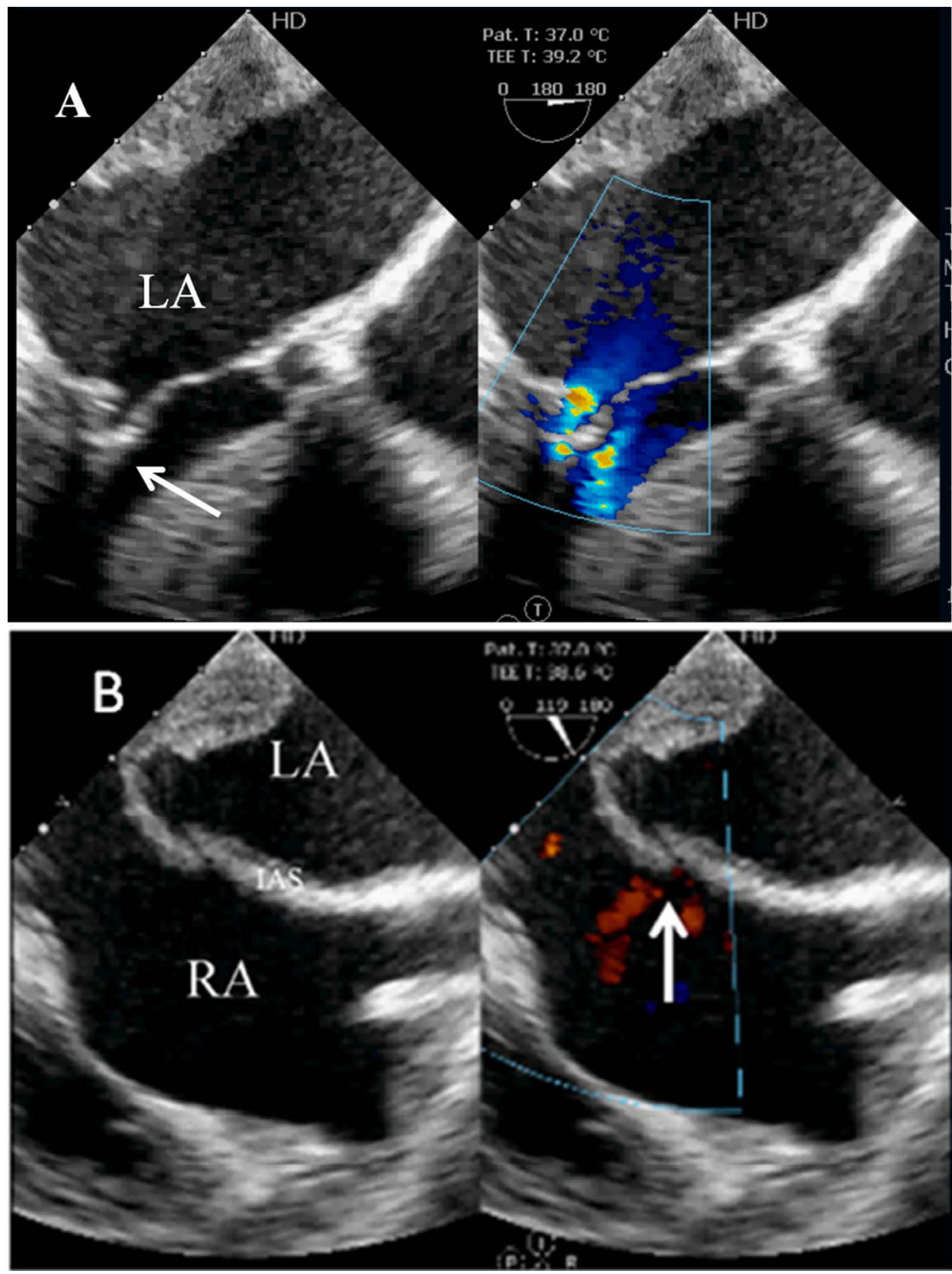

Figure 1 (A) Giant left atrium with a large clot and a ligated appendage. (B) Large clot in a different plane. 

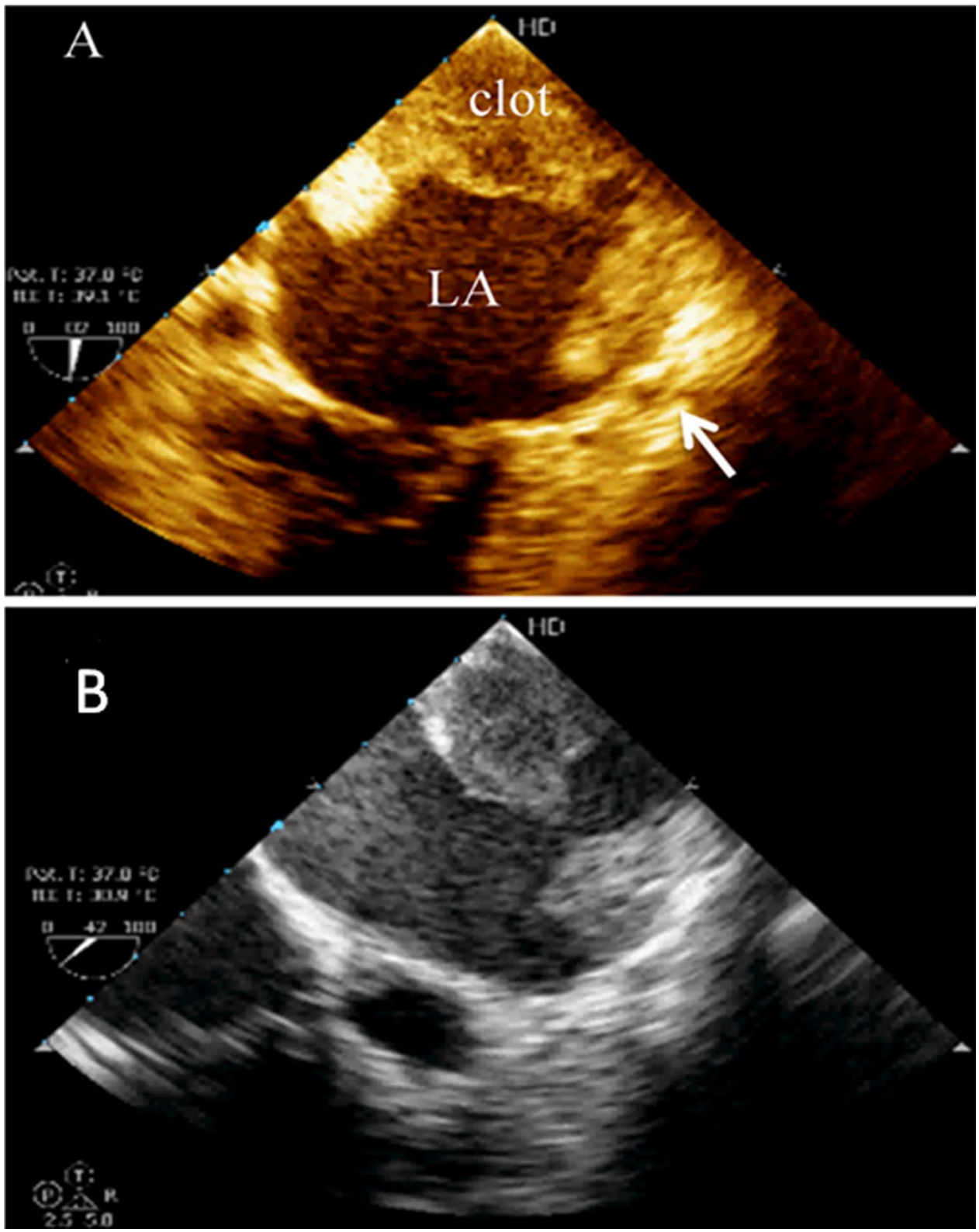

Figure 2 (A) Severe mitral stenosis with submitral fusion. (B) Small atrial septal defect secondary to previous septal puncture during percutaneous transvenous mitral commissurotomy.

(LA) clot who was successfully managed with surgery. A 45 -year-old female patient, who is a known case of RHD since childhood, had undergone a CMV with ligation of the left-atrial appendage 18 years prior, a PTMC 5 years prior, now presented with a history of progressive dyspnoea for 6 months. Clinical evaluation found an irregular pulse of $80 \mathrm{bpm}$, a blood-pressure of $110 / 70 \mathrm{~mm} \mathrm{Hg}$, mid-diastolic murmur at apex and a loud P2.

An ECG showed atrial fibrillation (AF); a chest X-ray showed large LA without an appendage and transthoracic echocardiogram (TTE) showed a small roof clot. Hence the patient was subjected to a transoesophageal echocardiogram (TEE) before considering for a redo PTMC.

The TEE images (figures 1 and 2 and videos 1 and 2) showed the multiple aspects of rheumatic MS like large LA, large LA clot, absent LA appendage suggestive of past CMV, small atrial septal defect suggestive of prior PTMC, severe MS and submitral disease. This case illustrates the whole spectrum of rheumatic MS captured in these TEE images and also the fact that a

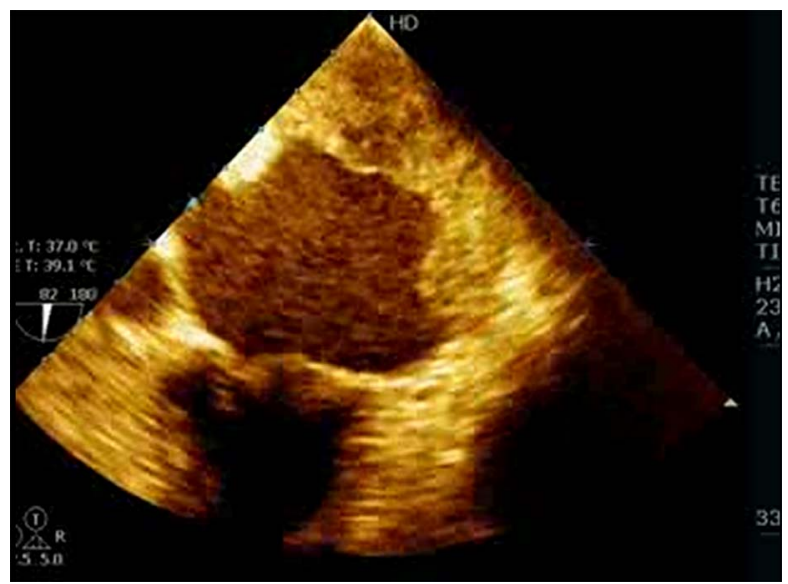

Video 1 TEE at 90 degrees two chamber view showing a Giant LA with a large clot of varying densities and an absent LAA. 


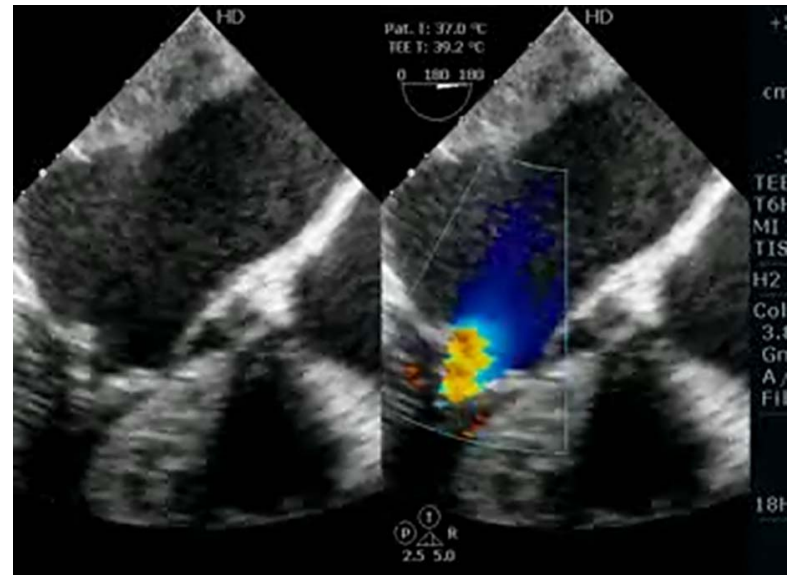

Video 2 TEE at 180 degrees four chamber view with colour Doppler compare showing severe mitral stenosis.

clot can form even in the absence of a LA appendage especially in patients with valvular AF. The size of the LA clot detected by TEE was much larger in contrast to TTE, highlighting the importance of TEE in the evaluation of an LA clot. Our patient underwent surgery in view of a large LA clot. However, PTMC can still be performed in the presence of an LA clot in selected patients, if the clot is above the level of fossa ovalis, using over-the-wire technique. ${ }^{3}$

\section{Learning points}

- Rheumatic mitral stenosis, highly prevalent in developing countries, can present with restenosis inspite of all available modalities of treatment.

- A clot can form in the left atrium (LA), even in the absence of an LA appendage especially in patients with valvular atrial fibrillation.

- Percutaneous transvenous mitral commissurotomy can be performed even in presence of clots in selected patients.

Competing interests None.

Patient consent Obtained.

Provenance and peer review Not commissioned; externally peer reviewed.

\section{REFERENCES}

1 Inoue K, Owaki T, Nakamura T, et al. Clinical application of transvenous mitral commissurotomy by a new balloon catheter. J Thorac Cardiovasc Surg 1984;87:394-402.

2 Ben Farhat M, Ayari M, Maatouk F, et al. Percutaneous balloon versus surgical closed and open mitral commissurotomy seven-year follow-up results of a randomized trial. Circulation 1998;97:245-50.

3 Manjunath CN, Srinivasa KH, Ravindranath KS, et al. Balloon mitral valvotomy in patients with mitral stenosis and left atrial thrombus. Catheter Cardiovasc Interv 2009;74:653-61.

Copyright 2013 BMJ Publishing Group. All rights reserved. For permission to reuse any of this content visit http://group.bmj.com/group/rights-licensing/permissions.

BMJ Case Report Fellows may re-use this article for personal use and teaching without any further permission.

Become a Fellow of BMJ Case Reports today and you can:

- Submit as many cases as you like

- Enjoy fast sympathetic peer review and rapid publication of accepted articles

- Access all the published articles

- Re-use any of the published material for personal use and teaching without further permission

For information on Institutional Fellowships contact consortiasales@bmjgroup.com

Visit casereports.bmj.com for more articles like this and to become a Fellow 